\title{
Prevention of Primary ACL Injuries: A Novel, Innovative Approach
}

\author{
Radu Fleaca', Mihai Roman', Tiberiu Bățagă², Andrei-Marian Feier², Radu Prejbeanu³, Vlad \\ Predescu4, Sándor-György Zuh², István Gergely², Octav Russu² \\ 1 "Victor Papillan" Faculty of Medicine, "Lucian Blaga” University, Sibiu, Romania \\ 2 University of Medicine and Pharmacy, Tîrgu Mureș, Romania \\ 3 "Victor Babeș" University of Medicine and Pharmacy, Timișoara, Romania \\ 4 "Carol Davila" University of Medicine and Pharmacy, Bucharest, Romania
}

\section{CORRESPONDENCE}

\begin{abstract}
Andrei Marian-Feier
Str. Gheorghe Marinescu nr. 38

540139 Tîrgu Mureș, Romania

Tel: +40 747501392

E-mail: andreifeier@gmx.com
\end{abstract}

\section{ARTICLE HISTORY}

Received: April 24, 2017

Accepted: May 13, 2017

Radu Fleaca • Str. Lucian Blaga nr. 2A, 550169 Sibiu, Romania. Tel: +40 269212 320, E-mail: rfleaca@ yahoo.com

Mihai Roman • Str. Lucian Blaga nr. 2A, 550169 Sibiu, Romania. Tel: +40 269212 320, E-mail: mihaidanroman@yahoo.com

Tiberiu Bățagă • Str. Gheorghe Marinescu nr. 38 540139 Tîrgu Mureș, Romania. Tel: +40 265215551 , E-mail: tbataga@gmail.com

Radu Prejbeanu • P-ța Eftimie Murgu nr. 2, 300041 Timișoara, Romania. Tel: +40 256204 400, E-mail: raduprejbeanu@gmail.com

Vlad Predescu • B-dul Eroii Sanitari nr. 8, 050474 Bucuresti, Romania. Tel: +40 213180 719, E-mail: vladpredescu001@gmail.com

Sándor-György Zuh • Str. Gheorghe Marinescu nr. 38, 540139 Tîrgu Mureș, Romania. Tel: +40 265215551. E-mail: zuh.sandor@gmail.com

István Gergely • Str. Gheorghe Marinescu nr. 38 540139 Tîrgu Mureș, Romania. Tel: +40 265215551. E-mail: gergelyistvan@studium.ro

Octav Russu • Str. Gheorghe Marinescu nr. 38, 540139 Tîrgu Mureș, Romania. Tel: +40 265215551 E-mail: octav@genunchi.ro

\begin{abstract}
Anterior cruciate ligament (ACL) injuries are increasing amongst professional and recreational athletes, and creating prevention programs to reduce the occurrence of $A C L$ damages is becoming a necessity. To prevent an ACL tear, it is necessary to comprehend the mechanisms and the risk factors of injury. Biomechanical and clinical studies try to understand these complex mechanisms in order to identify factors that can be improved and to develop training programs to prevent at least non-contact $A C L$ injuries. There are several promising programs, but there are still many questions to answer. This paper analyzes the risk factors for ACL injuries and some aspects of the modern programs developed to decrease the rate of ACL tears.
\end{abstract}

Keywords: anterior cruciate ligament injury, knee, instability, prevention, risk factors

\section{INTRODUCTION}

Anterior cruciate ligament (ACL) injuries are commonly encountered in professional and recreational athletes. There are many scientific projects aimed towards ACL injury treatment plans, but there is still a significant percentage of reconstruction failures with important long- term disabilities, reduced knee function, and significantly increased risk of developing knee osteoarthritis. ${ }^{1}$ Analyzing the mechanism of ACL rupture, McNair and Boden found in 1990 and 2000 respectively, that around seventy percent of ACL tears take place as a noncontact injury and therefore might be, in theory, preventable., ${ }^{2,3}$ Creating prevention programs to decrease the incidence of ACL injuries is a logical step. In 1996 Caraffa et al. published for the first time a prospective study on the prophylaxis of ACL tears in soccer and showed that proprioceptive workout can meaningfully decrease the rate of ACL in these athletes. ${ }^{4}$ Even if initially the notion of ACL tear prevention was debatable, in recent years important research has been undertaken to prove that prevention programs can reduce the incidence of ACL 
injuries. An analysis of 7 studies on ACL injury prevention programs, carried out between 1999 and 2008, found that participation in a prevention program decreased the risk of non-contact ACL tear by $71 \%$ on average. ${ }^{5}$ Prevention programs can also diminish the rates of other knee and ankle injuries. ${ }^{6}$ To be effective, these programs must be followed throughout the season; this requires a combined effort from the athletes and their coaches.

The present paper aims to present an analysis of the risk factors involved in ACL injuries and the results of the prevention programs.

\section{RISK FACTORS}

There are several studies showing an increased risk of up to six times for females to have an ACL tear. ${ }^{7,8}$ This leads to the assumption that there are several gender-related factors that influence the risk of having an ACL tear.

Analyzing the factors that can influence the risk of ACL damage, we can describe non-modifiable and modifiable biological factors, and environmental factors. Non-modifiable factors cannot be influenced, therefore cannot be decreased by any prevention program. In 2007 Hewett et al. published a systematic review of studies analyzing the association between ACL injury and menstrual cycle. ${ }^{9}$ Certain studies found a significant risk of ACL tear in the pre-ovulatory phase and a lower injury rate in females taking contraceptive pills, but no definite indication that hormonal changes are linked with ACL injury or the use of oral contraception. Ligamentous laxity is considered to be a risk factor for ligament injuries, as it has been demonstrated by published studies. ${ }^{3,10}$ The increased posterior tibial plateau slope seems to be correlated with a significant risk for ACL tear due to the increased peak of ACL strain. ${ }^{11-13}$ Notch width seems to be an important anatomic factor correlated with the risk of ACL tear, given that a minor notch invades the ACL. ${ }^{14}$ Souryal et al. proposed the notch-width index and showed that notch-width narrowing was significantly correlated with non-contact ACL injuries. ${ }^{15}$ Chaudhari et $a l$. showed that ACL injured subjects had significantly lower ACL volumes compared with those measured in controls. ${ }^{16}$ This can be correlated with the findings of Dienst $e t$ al.: a lower notch-width index is linked to a smaller ACL. ${ }^{17}$ Another biological factor that correlates with ACL injury risk seems to be the maturation of the skeleton, muscles, and neurological function. There is no difference between pre-adolescent gender characteristics, but following maturation, males undergo an increase in strength and coordination, allowing an increased neuromuscular control with differences in jumping and landing. ${ }^{18,19}$
The modifiable factors involved in ACL injury risk are represented by neuromuscular imbalances. ${ }^{20}$ Hewett et al. named the neuromuscular disproportion that causes valgus collapse as the ligament dominance. ${ }^{20}$ In case of ligament dominance, the supportive muscle groups that are adjacent to the knee joint do not contract, leading to the absorption of ground reaction forces by static tissues such as ligaments, cartilage, and bone. There are several studies demonstrating that ligament dominance is a risk factor for ACL tear, with demonstrated increased side-to-side differences in case of female subjects. ${ }^{21,22}$ It seems that the posterior kinetic chain (gluteus, hamstrings, gastrocnemius-soleus) is of utmost importance in preventing ACL tears, even if all lower extremity muscular groups are responsible for dynamic knee steadiness. Improper dynamics of the muscles during landing leads to increased abduction times, thus increasing the load that is transmitted to the ACL. ${ }^{20}$ Another neuromuscular imbalance creating a risk for ACL tear has been named as quadriceps dominance by Hewett. ${ }^{20}$ This is described as a quadriceps-active landing technique; women activate their quadriceps muscular group more than men, resulting in a vertical extended landing posture rather than a flexed posture, with an increased protection for the ACL. Contraction of the quadriceps exerts a tension on the ACL, with a maximum in $0-30^{\circ}$ of knee flexion. An upright landing position mainly contracts the quadriceps, applying an anterior shear stress to the knee joint. ${ }^{23}$ Leg dominance is another face of neuro-muscular control, which refers to side-to-side asymmetry. Even if the majority of athletes have one dominant side for kicking or jumping, it seems that female athletes have increased side-to-side differences. ${ }^{20,24}$ Hewett considered a sportsperson to be leg-dominant when the muscle asymmetry was measureable. ${ }^{20} \mathrm{In}$ a study published in 2003 , Ford found that female basketball players landed with a significantly higher maximum valgus knee-angle on their nondominant side in comparison with their dominant part, finding not valid for males. ${ }^{22}$ The last neuromuscular misbalance described by Hewett is termed trunk dominance. This describes the lack of dynamic control of the trunk due to suboptimal core strength, generating larger movements in the lower extremity for compensation. Lateral trunk movement was the best predictor for ACL tear risk in a study published by Zazulak in 2007.25

Even if there might be not enough studies to definitively assign these factors as risk factors for ACL tears, the efficiency of preventing programs based on reducing neuromuscular imbalances support the importance of these factors. Fatigue might be a risk factor for ACL tears, described in a study published by Chappell in 2005, but there aren't enough data yet to firmly sustain the importance of 
this factor. ${ }^{26}$ There are many studies analyzing environmental factors as risk factors for ACL injury. These include the sport, weather conditions, and especially sports gear, the quality of equipment, footgear, surface, shoe-surface interface etc. The most studied sports that seem to have the highest potential for ACL injuries are: American football, Australian football, soccer, basketball, handball, and ski. ${ }^{27}$ Several studies showed a high risk of ACL tears in dry compared to wet conditions, in hot compared to cold season, or in pre-season. 28,29 Orchard in 2005 issued the results of a prospective study on Australian footballers and showed that grass type, additionally to ground hardness or weather conditions, would be accountable for a higher risk of noncontact ACL tears. ${ }^{30}$ An epidemiologic study conducted by Dragoo et al. in 2012 analyzing football players, found that the percent of ACL tears on artificial grass compared to natural grass was present in games, scrimmages, and practices, and across all divisions. ${ }^{31}$ Olsen in 2003 published a retrospective study on the Norwegian handball team and found an increased ACL tear risk on rubber floors. ${ }^{32}$ Ekstrand $e t$ al. did not find any differences between the use of natural or artificial grass when conducting a prospective study on injuries on elite footballers. ${ }^{33}$ It seems that there is scarce evidence to sustain the fact that increased friction forces in the shoe and ground surface are an important risk factor for ACL tears. Bere et al. published in 2011 a video analysis showing that ski equipment was the most important risk factor for ACL injury, followed by changes in snow conditions; ${ }^{34}$ icy conditions on the slope probably could be safer than aggressive snow conditions. There are many studies supporting the importance of environmental factors in ACL injuries, some specific for certain sports.

\section{PREVENTION PROGRAMS}

Even if there are some contradictory results and more studies are needed, we can say that at least some of the described factors definitely have a significant role in producing non-contact ACL tears. Considering that some risk factors for ACL injury are modifiable, preventing programs have been developed with the purpose to reduce ACL tears. Most studies on preventive programs aimed to change risk factors for ACL tears rather than decrease injury incidence. ${ }^{28,29}$ Even if male professional and recreational athletes comprise the biggest population of total ACL tears, the science behind prevention injury programs is based mainly on research conducted on female athletes, therefore researchers are not ready to offer optimal preventive plans for male sports players..$^{35}$ Prevention agendas center their attention on some key features of training: bal- ance, proprioception, plyometrics, strengthening, endurance, and stability. ${ }^{36}$ The first clinical research to examine the protecting mechanisms of a neuromuscular training schedule was carried out in 1999 by Hewett et al..$^{37}$ A group of athletes underwent a pre-season neuromuscular workout program focused on flexibility, plyometrics, and proper technique. They found an increased incidence of injuries in the untrained female group compared with the trained female group. In 2005 Mandelbaum et al. analyzed in a prospective study conducted on women soccer players the role of a prevention program they had developed, named Prevent injury and Enhance Performance (PEP), designed for ACL tear prevention. ${ }^{38}$ The PEP program (Table 1) is a 20-minute exercise program that replaces the normal warm-up routine. ${ }^{38}$ The study included 1,041 female athletes in the first year and 844 in the second year who underwent the program and were compared with matched athletes as control. There was an $88 \%$ decrease in ACL tearing within the 1st year, and a 74\% decrease in the second one.

Using the PEP program Gilchrist et al. evaluated, in a randomized controlled trial, the incidence of non-contact ACL injury in women's soccer. They found that the incidence of non-contact ACL tears was 3.3 times lower in the PEP group compared to controls, and that players in the PEP group with a history of ACL tear had a significantly lower chance of suffering additional injuries. ${ }^{39}$ Thompson et al., in 2016, published a study investigating the effects of the F-MARC $11+$ injury prevention protocol developed by Soligard in 2008, showing that the program may be effective in improving peak knee valgus moment, a risk factor for ACL injuries, during a double-leg jump in pre-adolescent athletes. Also, the program reduced overall injury rates, but it remained unknown if it reduced ACL injuries in particular. ${ }^{6,40}$

Many trials analyzed different neuromuscular training programs designed to reduce the risk for ACL tear in handball female players and showed to reduce in the incidence of overall ACL injury, even if the studies are underpowered. ${ }^{41}$ The efficacy of prevention programs in decreasing the incidence of ACL tearing was sustained by the results of meta-analyses published by Hewett in $2010^{20}$, Yoo in $2010^{36}$, and Sadoghi in 2012.42 There are several biomechanical and clinical studies and meta-analyses supporting the possibility of preventing ACL injury by using validated prevention training programs, but we need future research to determine the importance of neuromuscular imbalances and generate solutions to prevent non-contact ACL injuries. One significant difficulty in the implementation of prevention programs is compliance. Steffen et al. published a study in 2007 , in which adhesion to preventive programs was $24 \%$ of the number of teams, as a result 
TABLE 3. Prevent injury and Enhance Performance designed for $A C L$ injury prevention

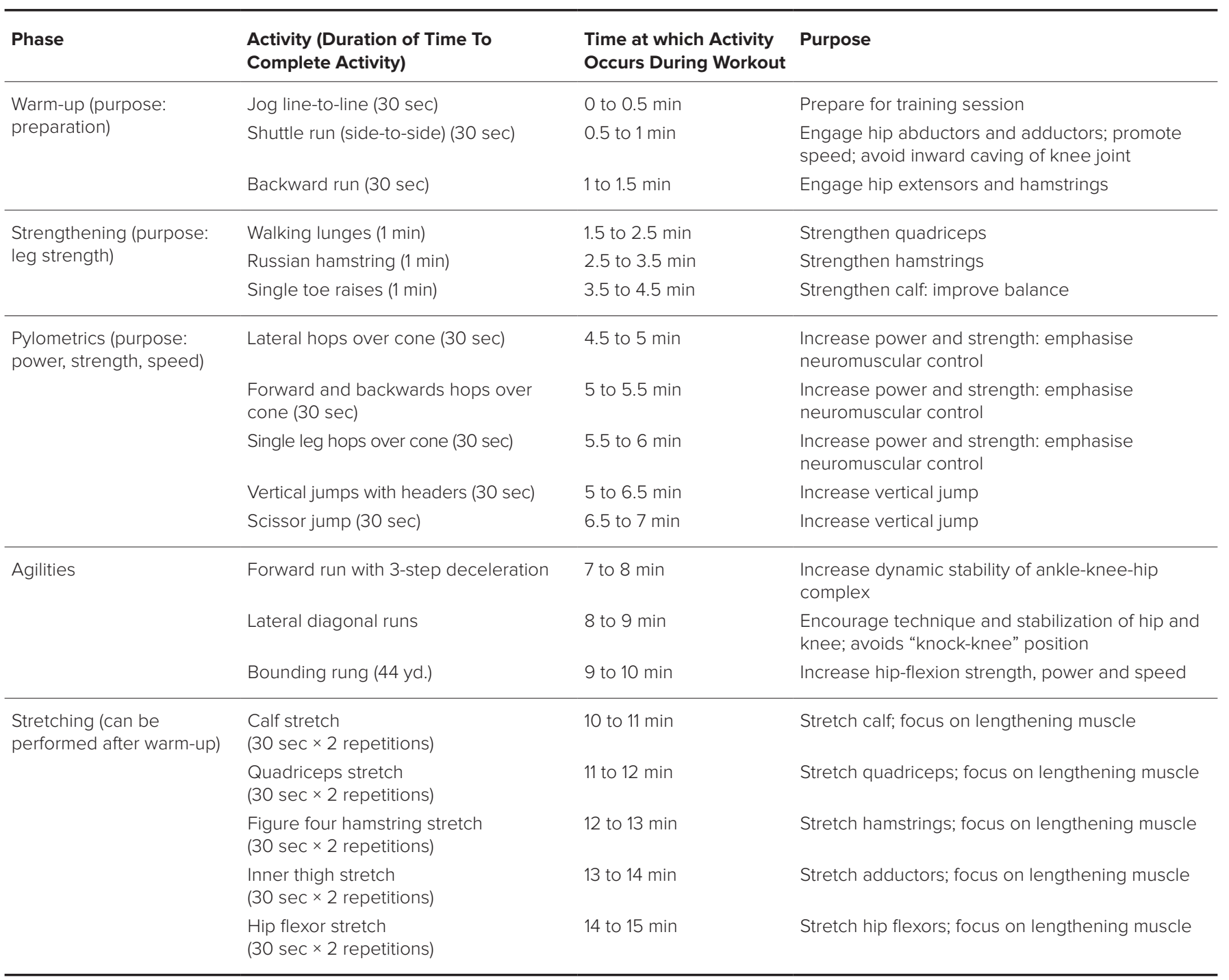

of the fact that instructors and athletes choose to focus on their performance rather than preventing injuries. ${ }^{43}$ This issue raises the question if prevention training programs should be applied to all athletes or just to the risk group. Myer et al. in 2013 conducted a screening study on women athletes divided into risk categories based on analyzing movement during a vertical jump and calculating knee abduction. ${ }^{35}$ They showed that peak knee abduction angle, quadriceps-to-hamstring ratio, knee-flexion range of motion, body mass index, and tibial length were the best predictors for knee abduction moments, with a sensitivity of $77 \%$ to $85 \%$ and a specificity of $71 \%$ to $93 \%$. In 2015 , the American Academy of Orthopedic Surgeons published the Appropriate Use Criteria for ACL Injury Prevention programs in order to determine the usefulness of using a supervised program for preventing ACL tears. ${ }^{44}$ Most votes were for an ACL injury prevention program that includes appropriate instruction and supervision, dynamic warmup, strength training, technique training, plyometrics, balance and proprioceptive training.

\section{CONCLUSIONS}

An increase in ACL injuries has been seen in the past years due to the growing number of athletes today. Even if there is not one specific way to injure an ACL, there are several different factors that intensify the risk for a non-contact ACL tear. It is accepted that females have a four to six time higher risk of ACL injuries than males, due probably to many different intrinsic factors, such as anatomical, biomechanical, and hormonal. Understanding the neuromuscular factors and environmental factors of an ACL injury allows physicians and therapists to develop programs that help decrease the rate of such injuries. 


\section{CONFLICT OF INTEREST}

\author{
Nothing to declare.
}

\section{REFERENCES}

1. Ekstrand J, Timpka T, Hagglund M. Risk of injury in elite football played on artificial turf versus natural grass: a prospective two-cohort study. $\mathrm{Br} \mathrm{J}$ Sports Med. 2006;40:975-980.

2. McNair PJ, Marshall RN, Matheson JA. Important features associated with acute anterior cruciate ligament injury. N Z Med J. 1990;103:537-539.

3. Boden BP, Dean GS, Feagin JA Jr, Garrett WE Jr. Mechanisms of anterior cruciate ligament injury. Orthopedics. 2000;23:573-578.

4. Caraffa A, Cerulli G, Projetti M, Aisa G, Rizzo A. Prevention of anterior cruciate ligament injuries in soccer. A prospective controlled study of proprioceptive training. Knee Surg Sports Traumatol Arthrosc. 1996;4:1921.

5. Kronemyer B. ACL-injury prevention programs found to be effective for female athletes. Orthopedics today: January 2011. Available at: http://www. orthosupersite.com/view.aspx?rid=79124

6. Soligard T, Myklebust G, Steffen K, et al. Comprehensive warm-up programme to prevent injuries in young female footballers: cluster randomized controlled trial. BMJ. 2008;337:a2469.

7. Agel J, Arendt EA, Bershadsky B. Anterior cruciate ligament injury in national collegiate athletic association basketball and soccer: a 13-year review. Am J Sports Med. 2005;33:524-530.

8. Mihata LC, Beutler Al, Boden BP. Comparing the incidence of anterior cruciate ligament injury in collegiate lacrosse, soccer, and basketball players: implications for anterior cruciate ligament mechanism and prevention. Am J Sports Med. 2006;34:899-904.

9. Hewett TE, Zazulak BT, Myer GD. Effects of the menstrual cycle on anterior cruciate ligament injury risk: a systematic review. Am J Sports Med. 2007;35:659-668.

10. Ramesh R, Von Arx O, Azzopardi T, Schranz PJ. The risk of anterior cruciate ligament rupture with generalised joint laxity. J Bone Joint Surg Br. 2005;87:800-803.

11. Todd MS, Lalliss S, Garcia E, DeBerardino TM, Cameron KL. The relationship between posterior tibial slope and anterior cruciate ligament injuries. Am J Sports Med. 2010;38:63-67.

12. McLean SG, Oh YK, Palmer ML, et al. The relationship between anterior tibial acceleration, tibial slope, and $\mathrm{ACL}$ strain during a simulated jump landing task. J Bone Joint Surg Am. 2011;93:1310-1317.

13. Rahnemai-Azar AA, Yaseen Z, van Eck CF, et al. Increased Lateral Tibial Plateau Slope Predisposes Male College Football Players to Anterior Cruciate Ligament Injury. J Bone Joint Surg Am. 2016;98:1001-1006.

14. Uhorchak JM, Scoville CR, Williams GN, Arciero RA, St Pierre P, Taylor DC. Risk factors associated with noncontact injury of the anterior cruciate ligament: a prospective four-year evaluation of 859 West Point cadets. Am J Sports Med. 2003;31:831-842.

15. Souryal TO, Freeman TR. Intercondylar notch size and anterior cruciate ligament injuries in athletes. A prospective study. Am J Sports Med. 1993;21:535-539.

16. Chaudhari AM, Zelman EA, Flanigan DC, Kaeding CC, Nagaraja HN Anterior cruciate ligament-injured subjects have smaller anterior cruciate ligaments than matched controls: a magnetic resonance imaging study. Am J Sports Med. 2009;37:1282-1287.

17. Dienst M, Burks RT, Greis PE. Anatomy and biomechanics of the anterior cruciate ligament. Orthop Clin North Am. 2002;33:605-620.

18. Hewett TE, Myer GD, Ford KR. Decrease in neuromuscular control about the knee with maturation in female athletes. J Bone Joint Surg Am. 2004;86:1601-1608.

19. Martin RJ, Dore E, Twisk J, van Praagh E, Hautier CA, Bedu M. Longitudinal changes of maximal short-term peak power in girls and boys during growth. Med Sci Sports Exerc. 2004;36:498-503.

20. Hewett TE, Ford KR, Hoogenboom BJ, Myer GD. Understanding and preventing $\mathrm{ACL}$ injuries: current biomechanical and epidemiologic considerations - update 2010. N Am J Sports Phys Ther. 2010;5:234-251.

21. Hewett TE, Myer GD, Ford KR, et al. Biomechanical measures of neuromuscular control and valgus loading of the knee predict anterior cruciate ligament injury risk in female athletes: a prospective study. Am J Sports Med. 2005;33:492-501.
22. Ford KR, Myer GD, Hewett TE. Valgus knee motion during landing in high school female andmale basketball players. Med Sci Sports Exerc. 2003;35:1745-1750

23. Withrow TJ, Huston LJ, Wojtys EM, Ashton-Miller JA. Effect of varying hamstring tension on anterior cruciate ligament strain during in vitro impulsive knee flexion and compression loading. J Bone Joint Surg Am. 2008;90:815-823.

24. Myer GD, Ford KR, Khoury J, Succop P, Hewett TE. Biomechanics laboratory-based prediction algorithm to identify female athletes with high knee loads that increase risk of ACL injury. Br J Sports Med. 2011;45:245252.

25. Zazulak BT, Hewett TE, Reeves NP, Goldberg B, Cholewicki J. Deficits in neuromuscular control of the trunk predict knee injury risk: a prospective biomechanical-epidemiologic study. Am J Sports Med. 2007;35:1123-1130.

26. Chappell JD, Herman DC, Knight BS, Kirkendall DT, Garrett WE, Yu B. Effect of fatigue on knee kinetics and kinematics in stop-jump tasks. Am J Sports Med. 2005;33:1022-1029.

27. Alentorn-Geli E, Myer GD, Silvers HJ, et al. Prevention of non-contact anterior cruciate ligament injuries in soccer players. Part 1: mechanisms of injury and underlying risk factors. Knee Surg Sports Traumatol Arthrosc. 2009;17:705-729.

28. Alentorn-Geli E, Mendiguchia J, Samuelsson K, et al. Prevention of anterior cruciate ligament injuries in sports. Part I: systematic review of risk factors in male athletes. Knee Surg Sports Traumatol Arthrosc. 2014;22:3-15.

29. Alentorn-Geli E, Mendiguchia J, Samuelsson K, MusahI V, Karlsson J, Cugat $\mathrm{R}$, Myer GD. Prevention of anterior cruciate ligament injuries in sports. Part II: systematic review of the effectiveness of prevention programmes in male athletes. Knee Surg Sports Traumatol Arthrosc. 2014;22:16-25.

30. Orchard JW, Chivers I, Aldous D, Bennell K, Seward H. Rye grass is associated with fewer non-contact anterior cruciate ligament injuries than Bermuda grass. Br J Sports Med. 2005;39:704-709.

31. Dragoo JL, Braun HJ, Harris AH. The effect of playing surface on the incidence of $\mathrm{ACL}$ injuries in National Collegiate Athletic Association American Football. Knee. 2012;20:191-195.

32. Olsen OE, Myklebust G, Engebretsen L, Holme I, Bahr R. Relationship between floor type and risk of $A C L$ injury in team handball. Scand J Med Sci Sports. 2003;13:299-304.

33. Ekstrand J, Hägglund M, Fuller CW. Comparison of injuries sustained on artificial turf and grass by male and female elite football players. Scand J Med Sci Sports. 2011;21:824-832.

34. Bere T, Florenes TW, Krosshaug T, Nordsletten L, Bahr R. Events leading to anterior cruciate ligament injury in World Cup Alpine Skiing: a systematic video analysis of 20 cases. Br J Sports Med. 2011:45:1294-1302.

35. Myer GD, Sugimoto D, Thomas S, Hewett TE. The influence of age on the effectiveness of neuromuscular training to reduce anterior cruciate ligament injury in female athletes: a meta-analysis. Am J Sports Med. 2013; 41:203-215.

36. Yoo JH, Lim BO, Ha M, Lee SW, Oh SJ, Lee YS, Kim JG. A meta-analysis of the effect of neuromuscular training on the prevention of the anterior cruciate ligament injury in female athletes. Knee Surg Sports Traumatol Arthrosc. 2010;18:824-830.

37. Hewett TE, Lindenfeld TN, Riccobene JV, Noyes FR. The effect of neuromuscular training on the incidence of knee injury in female athletes. A prospective study. Am J Sports Med. 1999;27:699-706.

38. Mandelbaum BR, Silvers HJ, Watanabe DS, et al. Effectiveness of a neuromuscular and proprioceptive training program in preventing anterior cruciate ligament injuries in female athletes: 2-year follow-up. Am J Sports Med. 2005;33:1003-1010

39. Gilchrist J, Mandelbaum BR, Melancon $\mathrm{H}$, et al. A randomized controlled trial to prevent noncontact anterior cruciate ligament injury in female collegiate soccer players. Am J Sports Med. 2008;36:1476-1483.

40. Thompson JA, Tran AA, Gatewood CT, et al. Biomechanical Effects of an Injury Prevention Program in Preadolescent Female Soccer Athletes. Am J Sports Med. 2017;45:294-301.

41. Postma WF, West RV. Anterior cruciate ligament injury-prevention programs. J Bone Joint Surg Am. 2013;95:661-669.

42. Sadoghi P, von Keudell A, Vavken P. Effectiveness of anterior cruciate ligament injury prevention training programs. J Bone Joint Surg Am. 2012;94:769-776

43. Steffen K, Andersen TE, Bahr R. Risk of injury on artificial turf and natural grass in young female football players. Br J Sports Med. 2007;41:i33-i37.

44. American Academy of Orthopedic Surgeons. Appropriate Use Criteria For ACL Injury Prevention Programs 2015. Available at: www.orthoguidelines. org/auc 